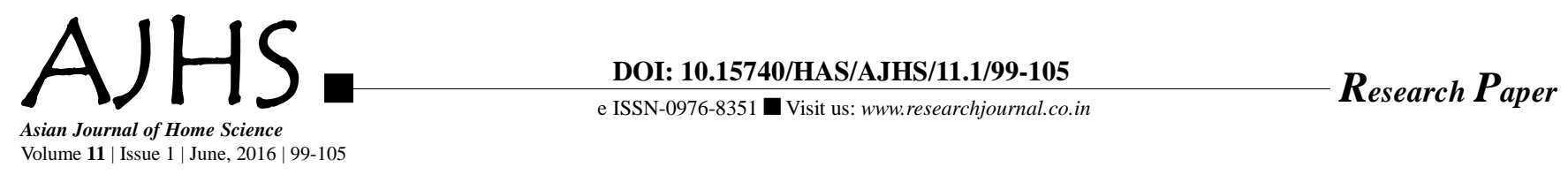

\title{
Nutritional status and traditional health culture of Tribal Women: A study in Mayurbhanj district, Odisha
}

Author for Correspondence :

\section{CHANDRASHREE LENKA}

Department of Home Science, R.D. Women's Junior College, BHUBANESWAR (ODISHA) INDIA Email : lenkachandrashree@yahoo. com
ABSTRACT : Every twelveth women in India belong to a tribal community, therefore improving their health status become an important development goal. Odisha has a sizable proportion of tribal population out of which 21 per cent are women in Odisha. A women health affects the household economic, well being and a women with poor health will be less productive in the labour force. Keeping these facts in mind the present research is designed to study the "Nutritional Status and Traditional Health culture of Tribal women in Odisha". One hundred literate tribal women of Jashipur block of Mayurbhanj districts of Odisha were selected by random purposive sampling method for the present study. The data was collected by questionnaire cum interview method. The results of the study revealed that majority of the respondents belonged to 25-40 years of age group having agriculture as primary occupation. All of them belong to low income group. Most of the respondents had normal BMI. Malaria and joint pain was their common health problem. 98 per cent of the respondents were non-vegetarian and were taking three meals per day. Parboiled price was their staple food. "Handia" prepared out of Rice and Bakhara was their common beverage. Milk and meat products, sugar and Jaggery, pulses were found to be less in their diet in comparison to RDA. Their diet was found to be excess in energy, iron and calcium. They were taking various types of foods to get relief from different diseases such as Bug with banana for piles, Handia rasi and Pedipedica leave for Jaundice, Burnt Skin and ear of goat for dyscentry etc. Different types of foods used by them related to reproduction were Palta medicine for son, babul leaves for fair baby, Runja seeds for abortion etc. Health practice for recovery from some type of health problems were burning with fire the effective area and putting bhalia on it for eczema, scald with hot iron on head for migrain etc. 100 per cent of the respondents were found to believe in magic treatment and herbal treatment for getting relief from their illness. Thus it can be concluded that there is an immense need to educate the women to improve their health status by wise use of available food stuffs and availing medical services during their diseased condition.

KEY WORDS: Nutritional status, BMI, Health Culture, Handia, RDA

— HOW TO CITE THIS PAPER : Lenka, Chandrashree (2016). Nutritional status and traditional health culture of Tribal Women: A study in Mayurbhanj district, Odisha. Asian J. Home Sci., 11 (1) : 99-105, DOI: 10.15740/HAS/AJHS/11.1/99-105. 